\title{
Measuring Better Care: Building the Evidence to Inform Policy and Practice Around Children's Care
}

\author{
Mark Canavera $^{1}$ - Florence Martin $^{2}$
}

Published online: 26 April 2016

(C) Springer International Publishing 2016

\section{Introduction}

Over the last 30 years, there has been a growing understanding of the critical importance of the family and a family environment for children in terms of their development and well-being. This realization is at the core of the United Nations Convention on the Rights of the Child, adopted in 1989 (UN General Assembly 1989), and more recently of the Guidelines for the Alternative Care of Children, welcomed by the United Nations General Assembly in 2009 (UN General Assembly 2010). A major body of empirical research in psychology and neuroscience has demonstrated the importance of investment in children's early years to support this critical period of child development (Shonkoff and Phillips 2010). Findings into the negative impact of emotional deprivation and institutionalization for younger children in Central and Eastern Europe further reinforced the critical importance of parental care and a family environment (Berens and Nelson 2015, Fox et al. 2011, National Scientific Council on the Developing Child 2012, Nelson et al. 2011, Schoenmaker et al. 2014, van Ijzendoorn et al. 2011). Although data on children in all forms of residential care continue to be far too limited, where research has been conducted, it has confirmed that the commonly used term "orphanage" to refer to these facilities is a misnomer. The vast majority of children in institutional care (estimates range from 80 to $90 \%$ ) have at least one living parent and for a majority, both parents are alive (Browne 2005, Browne et al. 2006, Carter 2005, Csáky 2009). In middle- and low-income

Mark Canavera

mc3718@cumc.columbia.edu

CPC Learning Network, Columbia University, New York, NY, USA

2 Better Care Network, New York, NY, USA countries, parents and families place children in residential care facilities due to a range of challenges undermining their capacity to care (Csáky 2009, Williamson and Greenberg 2010).

During the same period, the HIV and AIDS pandemic focused the attention of policymakers and researchers in the aid community on the importance of family care in the context of stresses and emergencies. In sub-Saharan Africa, the devastating impact of the pandemic on children's care situations and well-being, with spiraling numbers of parental deaths in highprevalence countries, led to high percentages of children being left to the care of extended families or communities, living in child-headed households, or living in barely functional alternative care systems, particularly residential care facilities (UNAIDS et al. 2004). As a growing body of evidence was gathered and programs deployed to respond to the AIDS crisis, it also became clear that other factors beyond parental death were affecting children's care situations and their wellbeing outcomes. Research findings in a range of countries in Eastern and Southern Africa, for example, highlighted that while orphanhood was a key indicator of child vulnerability, other factors seemed to play an equally significant or even greater role in terms of child well-being and development, including household poverty and also gender (Campbell et al. 2010). A recent study by UNICEF (2014), which reviewed the utility of existing markers of child vulnerability, based on the UNICEF and UNAIDS definition of a child made vulnerable by HIV/AIDS, found that a child's living arrangement was a stronger marker of well-being than orphanhood status. The same analysis demonstrated that children living with people other than their parents were found to fare worse in almost every outcome area than children living with parents.

Furthermore, a range of qualitative studies have deepened our understanding of the diversity of children's care 
arrangements and living situations in both emergency and non-emergency contexts, including in countries with low HIV prevalence. In particular, there has been increasing recognition of the critical role that informal care plays in a range of contexts as well as the need to understand informal support in a more comprehensive way to inform social policies and programs for particularly vulnerable children and their caregivers (Roby 2011).

Reforms of child protection and the development of alternative care systems for children deprived of parental care, or at risk of becoming so, have been ongoing in virtually all regions of the world; these efforts include a particular focus on moving away from the use of residential care and strengthening the capacity of parents and families to care for their children (Better Care Network and UNICEF 2015). Beyond nationallevel efforts, this redirection of support towards child- and family-centered policies and services has become a key part of bilateral and multilateral social development policies. Examples of this include the European Commission's 2013 "Recommendation on Investing in Children" (European Commission 2013) and the US Government's groundbreaking "Action Plan on Children in Adversity" that makes strengthening family care and preventing unnecessary childfamily separation one of the principle objectives for US development assistance for vulnerable children globally (US Government 2012, Objective 2).

\section{Rationale for the Special Issue}

Despite these important normative advancements to promote family-based care for children, measurement of critical issues related to children's care remains a challenge. Greater understanding of the diversity of children's care arrangements - as well as the impacts of policies and programs intended to prevent unnecessary child-family separation while improving alternative care options and decisions - remains a high priority for those working to bolster children's well-being and development. The wide-ranging gaps in current understanding and knowledge related to trends and patterns in children's care and the provision of alternative care, in both formal and informal settings, make it difficult to know what programs and approaches will be most effective in realizing these ideals. For example, there is no systematic assessment of the numbers of children deprived of parental care across countries or of the number of children who are at risk of such separation. Although it is known that the vast majority of children not living with their parents are in extended family care, there is remarkably little data about these care arrangements and how best to strengthen them to ensure positive care outcomes for children. Moreover, there is a lack of cohesive data on the various programs that are attempting to reform child care in different countries and of solid understanding of "what works" when it comes to carrying out this work. These gaps in knowledge and learning make it extremely difficult for individual countries or international development experts to support strategic child care reform.

The Society for Research in Child Development's so-called Leiden Monograph, which sought to synthesize current learning concerning care for children without permanent parental care in 2011, indicated that there remain "some fundamental issues of research, practice, and policy that are largely unsettled or controversial" (McCall 2011, 223). While acknowledging that research pertaining to children without adequate parental care "represents an exceedingly tough scholarly nut to crack..., especially true in the study of children subjected to early adversity, primarily institutionalization," it concludes that the complex research questions that remain could be answered through additional political will and the mobilization of resources to answer these questions (McCall 2011, 224).

To that end, this special issue of Global Social Welfare represents an effort to present state-of-the-art learning about how to measure issues related to children's care in a way that informs more effective policies and programs. The issue grows out of a 2014 symposium co-hosted by the Better Care Network and the CPC Learning Network at New York University's McSilver Institute for Poverty Policy and Research, an event that convened a number of leading academics, policymakers, and practitioners involved in the development or implementation of key initiatives to better measure issues of children's care at country, regional, and international levels.

This issue can be read in three sections. The first section presents recent efforts to improve the measurement of largescale trends in family structure and composition as well as children's care and living arrangements. The second explores policy and program effectiveness concerning efforts to strengthen family-based care for children. The third section presents initiatives to better understand the situation of children living outside of family care.

Section 1: Measuring Trends in Families and Children's Care and Living Arrangements

Understanding better those situations that make children "care vulnerable" - including children at risk of child-family separation as well as those already outside of family care - has become crucial for all countries seeking to strengthen their responses and systems for children facing a range of care and protection risks. Data on trends on family composition and children's living and care arrangements are routinely used in high-income countries to inform policies targeted at particularly vulnerable families, policies having the clear aim of strengthening parental capacity and addressing risk factors associated with child-family separation and the loss of family care (e.g., OECD 2016). A number of organizations working to support reforms of child care and protection systems in low- 
and middle-income countries have highlighted the potential for more systematic mining of existing household level data sets, particularly from Demographic and Health Surveys (DHS) and Multiple Indicators Cluster Surveys (MICS), to provide a better picture of the patterns and trends relating to children in households who are not living with a biological parent (Family for Every Child and INTRAC 2012; Roby 2011; Child Frontiers 2012; Better Care Network 2015a, b, c, 2016a, b; Save the Children 2015). The issue's first article, "Who cares for children?" by Martin and Zulaika, makes a powerful argument about the need to better mine these existing data sources and demonstrates how to do so in the countries where DHS and MICS data are regularly collected. It also highlights some of the limitations of those data sets and calls for strengthening these survey questionnaires so that critical data can be made available in middle- and low-income countries to inform policies and services to strengthen parental capacity and prevent unnecessary separation. Other important initiatives, such as Child Trends' World Family Map Project, are demonstrating the potential of using internationally comparative data to map trends in family structures, family processes, and culture and to explore the links between these indicators and certain outcomes of child well-being. Scott and Karberg, in the issue's second article, "Measuring children's care arrangements and their educational and health outcomes internationally," describe the methodology for creating the World Family Map and demonstrate how linkages between children's care arrangements and their educational and health outcomes can be evaluated in settings around the world. Taken together, these two articles meaningfully demonstrate that some large-scale, population-level data on children's care arrangements are already available in countries throughout the world for policymakers, researchers, and programmers to make use of as they explore how children's care situations impact children's development.

\section{Section 2: Determining the Effectiveness of Policies and Programs}

Beyond understanding trends in family composition and living arrangements and how these relate to child well-being outcomes, there is also a growing body of research seeking to measure the impact of interventions targeted at vulnerable families to strengthen their capacity to care for their children, to prevent unnecessary separation, and to provide appropriate alternative care when a child's best interest is not to remain in the care of his or her family. What approaches are being used to measuring the impact of care reform and family strengthening interventions in a range of contexts? What are we learning, and what are the challenges? Those questions form the focus of this section of the issue.

Care reforms have been informed by research that has shown that the vast majority of children in residential care are not placed there because care is genuinely needed or because they are without parental or family care but rather because their families are facing a range of challenges in their capacity to care; these challenges include poverty, lack of access to social services, discrimination, and social exclusion as well as personal or social crises and emergencies (Csáky 2009, Williamson and Greenberg 2010). As a result of such learning, governments and other stakeholders in these reform processes have recognized that a major focus of this shift away from the use of residential care for children should not simply seek to reduce the numbers of institutions and remove children from them but also should aim to establish better preventive and family support services to reduce child-family separation and to prevent children going into alternative care in the first place. Family strengthening interventions comprised of both financial and psychosocial interventions are increasingly being developed and tested in a range of country contexts and situations, including low- and middle-income countries (Knerr et al. 2013). Important efforts are also underway to understand and measure the impact of household-level economic strengthening interventions on strengthening families' economic capacity to withstand shocks and stresses as well as on addressing the impact of chronic poverty and inequity on families' ability to access basic social services, in particular education (Reisch Sinclair et al. 2013; Harper et al. 2012). The extent to which these interventions - be they targeted or universal social transfers - serve effectively to prevent unnecessary child-family separation and to support children's care in their families has important implications for child- and family-centered social policies (Barrientos et al. 2013).

The three articles included in this section of the issue probe the issue of policy and program effectiveness in important ways. In the conceptual piece "Early Family Support Interventions: Creating Context for Success," Daro turns a critical eye to many effectiveness studies, noting that interventions that work in one context are rarely transferable to another. Making a persuasive case for the need for deep contextualization of interventions, Daro makes recommendations that will be useful to policymakers and practitioners in both the USA and internationally. In the following piece, "The Value Added Impact of Fast-Track Adoption Policy on Adoption Rates," Wulczyn and colleagues undertake statistical analyses to determine that "fast-track" adoption policies in place in some American states do not, in fact, seem to translate into higher rates of adoption. The authors carefully probe some of the policy and practice implications of these findings, noting that policies do not always lead to their intended outcomes. Finally, in a mixed methods study from Côte d'Ivoire, Muriuki and colleagues demonstrate the powerful impact of a "community caregiver model" of service delivery in that country, showing that children and families who receive services through this model are likely to experience significantly greater access to services, the first step in their path to 
improved health and other outcomes. All three articles demonstrate that creating effective policies and translating them into effective practice for children whose care situations are vulnerable are complex endeavors that require ongoing learning and adaptation.

\section{Section 3: Improving Learning about Children in Alternative Care}

Implementation of international standards on children's care, including the Guidelines for the Alternative Care of Children, are guiding reforms of care and protection systems across all regions. Under these standards, states have the responsibility to support parents and caregivers in their child-rearing roles but also to oversee and ensure the provision of a range of alternative care options, prioritizing family-based ones (UN General Assembly 1989, articles 7, 9, 18, and 20, and UN General Assembly 2010, section II.A and IV.A). Major questions remain concerning how states are measuring up to these standards as well as how progress towards the implementation of these guidelines can be assessed and monitored. Data on children in alternative care are notoriously poor with weak information management systems at the national level combined with ineffective regulatory systems; together, these gaps mean that children's placements in alternative care are rarely recorded and that a significant proportion of alternative care providers, particularly those representing residential facilities, are unregistered and unknown to the authorities (Better Care Network and UNICEF 2015). Major efforts are underway to strengthen these systems and to support better information and improved understanding of the numbers and situations of children in alternative care.

A range of actors are working at the global, regional, and national levels to support the implementation of international and regional standards for children's care; many are collaborating to ensure that appropriate national-level indicators, tools, and information management systems are available to gauge progress and to encourage learning across countries and regions (Better Care Network and UNICEF 2009; Cantwell et al. 2012). An inter-agency working group led by Better Care Network and Save the Children, supported by the Centre for Excellence for Looked after Children in Scotland, is developing a tool to track and monitor country-level implementation of the Guidelines for the Alternative Care of Children (Martin 2015). The US Government's National Action Plan on Children in Adversity has also highlighted "children outside of family care" as a priority issue and issued national-level guidelines for strategies to enumerate children outside of family care (US Government 2012; Stark et al. 2014). Taken together, these initiatives are intended to enable countries to measure progress, allowing policymakers to review the extent to which their care systems are compliant with international standards and providing them with effective directions to bridge the identified gaps.

The three articles in this final section each take a different approach to improve our understanding of children in alternative care situations. The first, "A Forgotten Population" by Stark and Rubenstein, is a methodological exposition of efforts to estimate quantitatively the number and profile of children living outside of households in Cambodia. Ruiz-Casares and Phommavo ng in "Determinants and Consequences of Children Living Outside of Parental Care in Lao People's Democratic Republic" then provide a rich, grounded view as perceived by both young people and adults concerning the situation of children living outside of parental care in that country. In the issue's final article, "Using child wellbeing assessments to track progress in family-based reintegration," Wakia and Corcoran describe the organization Retrak's efforts to integrate quantitative measures into programs supporting children who are reintegrating families after time spent living and working on the street. These three articles - as well as those that precede them - stand at the cutting edge of measurement efforts for children's care, and we hope that you learn as much reading them as we have enjoyed editing this volume.

In closing, we send our special thanks to the Editor-inChief Dr. Mary McKay and Ms. Ammu Kowolik, Managing Editor of Global Social Welfare, for the trust that they have placed in us in editing this volume, which we hope will advance the conversation around measurement of children's care issues.

\section{References}

Barrientos, A., Byrne, J., Villa, J.M., and Peña, P. (2013). Social transfers and child protection. UNICEF Office of Research and Brooks World Poverty Institute. Retrieved 8 April 2016, from http://www. bettercarenetwork.org/library/social-welfare-systems/socialprotection-policies-and-programmes/social-transfers-and-childprotection

Berens, A. E., \& Nelson, C. A. (2015). The science of early adversity: is there a role for large institutions in the care of vulnerable children? Lancet, 386(9991), 388-98. doi:10.1016/S0140-6736(14)61131-4.

Better Care Network. (2015a). Ethiopia: children's care and living arrangements, DHS 2011. Retrieved 8 April 2016, from http://www. bettercarenetwork.org/library/social-welfare-systems/data-andmonitoring-tools/ethiopia-children's-care-and-living-arrangementsdhs-2011

Better Care Network. (2015b). Liberia: children's care and living arrangements DHS 2013. Retrieved 8 April 2016, from http://www. bettercarenetwork.org/library/social-welfare-systems/data-andmonitoring-tools/liberia-childrens-care-and-living-arrangementsdhs-2013

Better Care Network. (2015c). Tanzania: children's care and living arrangements DHS 2010. Retrieved 8 April 2016, from http://www. bettercarenetwork.org/library/social-welfare-systems/data-and- 
monitoring-tools/tanzania-children $\% \mathrm{E} 2 \% 80 \% 99$ s-care-and-livingarrangements-dhs-2010

Better Care Network. (2016a). Ghana: children's care and living arrangements, DHS 2014. Retrieved 8 April 2016, from http://www. bettercarenetwork.org/library/social-welfare-systems/data-andmonitoring-tools/ghana-children $\% \mathrm{E} 2 \% 80 \% 99$ s-care-and-livingarrangements-dhs-2014

Better Care Network. (2016b). Sierra Leone: children's care and living arrangements, DHS 2013. Retrieved 8 April 2016, from http://www. bettercarenetwork.org/library/social-welfare-systems/data-andmonitoring-tools/sierra-leone-children $\%$ E2\%80\%99s-care-andliving-arrangements-dhs-2013

Better Care Network and UNICEF. (2009). Manual for the measurement of indicators for children in formal care. Retrieved 8 April 2016, from http://bettercarenetwork.org/library/social-welfare-systems/ data-and-monitoring-tools/manual-for-the-measurement-ofindicators-for-children-in-formal-care-pdf

Better Care Network and UNICEF. (2015). Making decisions for the better care of children: the role of gatekeeping in strengthening family-based care and reforming alternative care systems. Retrieved 8 April 2016, from http://www.bettercarenetwork.org/ library/principles-of-good-care-practices/gatekeeping/makingdecisions-for-the-better-care-of-children-the-role-of-gatekeepingin-strengthening-family

Browne, K. (2005). A European survey of the number and characteristics of children less than three years old in residential care at risk of harm. Adoption \& Fostering, 29(4), 23-33. doi:10.1177/ 030857590502900405 .

Browne, K., Hamilton-Giachritsis, C., Johnson, R., \& Ostergren, M. (2006). Child health: overuse of institutional care for children in Europe. BMJ [British Medical Journal], 332(7539), 485.

Campbell, P., Handa, S., Moroni, M., Odongo, S., \& Palermo, T. (2010). Assessing the 'orphan effect' in determining development outcomes for children in 11 eastern and southern African countries. Vulnerable Children and Youth Studies, 5(1), 12-32.

Cantwell, N., Davidson, J., Elsley, S., Milligan, I., and Quinn, N. (2012). Moving Forward: Implementing the "Guidelines for the Alternative Care of Children." UK: Centre for Excellence for Looked After Children in Scotland. Retrieved 8 April 2016, from http://www. bettercarenetwork.org/library/particular-threats-to-childrens-careand-protection/child-abuse-and-neglect/moving-forwardimplementing-the-guidelines-for-the-alternative-care-of-children

Carter, R. (2005). Family matters: a study of institutional childcare in Central and Eastern Europe and the Former Soviet Union. London: Everychild.

Child Frontiers. (2012). Family support services and alternative care in Sub-Saharan Africa: background paper. Retrieved 8 April 2016, from http://www.bettercarenetwork.org/library/strengtheningfamily-care/parenting-support/family-support-services-andalternative-care-in-sub-saharan-africa-background-paper

Csáky, C. (2009). Keeping children out of harmful institutions. Save the Children UK. Retrieved 8 April 2016, from http://www. savethechildren.org.uk/resources/online-library/keeping-childrenout-of-harmful-institutions-why-we-should-be-investing-in-familybased-care

European Commission. (2013). Recommendation of 20 February 2013. Investing in children: breaking the cycle of disadvantage (2013/112/ EU). Official Journal of the European Union. L 59/5. Retrieved 8 April 2016, from http://www.bettercarenetwork.org/library/socialwelfare-systems/cost-of-care-and-redirection-of-resources/eucommission-recommendation-2013112eu-on-investing-in-children

Family for Every Child and INTRAC. (2012). Context for children and policy situation paper. Retrieved 8 April 2016, from http://www. familyforeverychild.org/report/context-for-children-and-policysituation-paper-2/
Fox, N. A., Almas, A. N., Degnan, K. A., Nelson, C. A., \& Zeanah, C. H. (2011). The effects of severe psychosocial deprivation and foster care intervention on cognitive development at 8 years of age: findings from the Bucharest Early Intervention Project. Journal of Child Psychology and Psychiatry, 52(9), 919-928.

Harper, C., Jones, N., Mendoza, R., Stewart, D., \& Strand, E. (Eds.). (2012). Children in crisis: seeking child-sensitive policy responses. Rethinking International Development Series. New York: Springer.

Knerr, W., Gardner, F., \& Cluver, C. (2013). Improving positive parenting skills and reducing harsh and abusive parenting in low- and middleincome countries: a systematic review. Prevention Science, 14(4), $352-363$.

McCall, R. B. (2011). IX. Research, practice, and policy perspectives on issues of children without permanent parental care. Monographs of the Society for Research in Child Development, 76(4), 223-272. doi: 10.1111/j.1540-5834.2011.00634.x.

Martin, F. (2015). Tracking progress initiative: monitoring the guidelines' implementation, ISS Monthly Review, 1 March 2015. Retrieved 8 April 2016, from http://www.bettercarenetwork.org/library/socialwelfare-systems/data-and-monitoring-tools/tracking-progressinitiative-monitoring-the-guidelines $\% \mathrm{E} 2 \% 80 \% 99$-implementation

National Scientific Council on the Developing Child. (2012). The science of neglect: the persistent absence of responsive care disrupts the developing brain: Working Paper 12. Retrieved 13 April 2016, from: http://developingchild.harvard.edu/resources/the-science-ofneglect-the-persistent-absence-of-responsive-care-disrupts-thedeveloping-brain/

Nelson, C. A., Bos, K., Gunnar, M. R., \& Sonuga-Barke, E. J. (2011). V. The neurobiological toll of early human deprivation. Monographs of the Society for Research in Child Development, 76(4), 127-146.

Organisation for Economic Co-operation and Development. (2016). OECD Family Database. Retrieved 8 April 2016, from http:// www.oecd.org/els/family/database.htm

Reisch Sinclair, M., Carmichael, J., Diener, O., and Rutherford, D. (2013). Why measuring child-level impacts can help achieve lasting economic change. USAID, CPC Learning Network, Women's Refugee Commission, and FHI 360. Retrieved 8 April 2016, from http://www.seepnetwork.org/why-measuring-child-level-impactscan-help-achieve-lasting-economic-change-resources-1216.php

Roby, J. (2011). Children in informal alternative care: discussion paper. New York, NY: UNICEF. Retrieved 8 April 2016, at http://www. unicef.org/protection/Informal_care discussion_paper_final.pdf

Save the Children. (2015). A sense of belonging: understanding and improving informal alternative care mechanisms to increase the care and protection of children. Retrieved 8 April 2016, from http:// resourcecentre.savethechildren.se/sites/default/files/documents/ final_regional_report_updated_21052015.pdf

Schoenmaker, C., Juffer, F., van IJzendoorn, M. H., \& BakermansKranenburg, M. J. (2014). Does family matter? The well-being of children growing up in institutions, foster care and adoption. In A. Ben-Arieh, F. Casas, I. Frønes, \& J. E. Korbin (Eds.), Handbook of child well-being: theories, methods and policies in global perspective (pp. 2197-2228). New York: Springer.

Shonkoff, J.P. and D.A. Phillips, eds. (2010). From neurons to neighborhoods: the science of early childhood development. National Academies Press: Committee on Integrating the Science of Early Childhood Development; Board on Children, Youth, and Families; Institute of Medicine; and Division of Behavioral and Social Sciences and Education. DOI: 10.17226/9824.

Stark, L., Rubenstein, B.L., Muldoon, K. and Roberts, L. (2014). Guidelines for implementing a national strategy to determine the magnitude and distribution of children outside of family care. Washington, DC: Center for Excellence on Children in Adversity. Retrieved 8 April 2016, from http://www.cpcnetwork.org/resource/ guidelines-for-implementing-a-national-strategy-to-determine-themagnitude-and-distribution-of-children-outside-of-family-care/ 
UN General Assembly. (20 November 1989). Convention on the Rights of the Child: adopted and opened for signature, ratification and accession by General Assembly resolution 44/25 of 20 November 1989 entry into force 2 September 1990, in accordance with article 49. Retrieved 8 April 2016, from http://www.ohchr.org/en/ professionalinterest/pages/crc.aspx

UN General Assembly. (24 February 2010). Guidelines for the Alternative Care of Children: resolution adopted by the General Assembly (A/RES/64/142). Retrieved 8 April 2016, from http:// www.un.org/en/ga/search/view_doc.asp?symbol=A/RES/64/142

UNAIDS, UNICEF, and USAID. (2004). Children on the Brink 2004: a joint report of new orphan estimates and a framework for action. Retrieved 8 April 2016, from http://www.unicef.org/publications/ index 22212.html

UNICEF. (2014). Measuring the determinants of childhood vulnerability. New York, NY: UNICEF. Retrieved 13 April 2016, from http://data. unicef.org/corecode/uploads/document6/uploaded_pdfs/corecode/ Measuring-the-Determinants-of-Childhood-Vulnerability_FinalReport-5 8-LR-_172.pdf

United States Government. (2012). Action plan on children in adversity: a framework for international assistance: 2012-2017. Washington, DC. Retrieved 13 April 2016, from https://www. childreninadversity.gov/about/how/action-plan

van Ijzendoorn, M. H., Palacios, J., Sonuga-Barke, E. J., Gunnar, M. R., Vorria, P., McCall, R. B., \& Juffer, F. (2011). I. Children in institutional care: delayed development and resilience. Monographs of the Society for Research in Child Development, 76(4), 8-30.

Williamson, J. and Greenberg, A. (2010). Families, not orphanages: Better Care Network Working Paper. Retrieved 8 April 2016, from http://www.bettercarenetwork.org/library/the-continuum-of-care/ foster-care/families-not-orphanages 